\title{
ANÁLISE DA PRODUÇÃO CIENTÍFICA SOBRE A NOTIFICAÇÃO DA VIOLÊNCIA CONTRA ADOLESCENTES
}

\author{
Analysis of the scientific production on the notification of \\ violence against adolescents \\ Análisis de la producción científica sobre la notificación de la \\ violencia contra adolescentes
}

Artigo de Revisão

\section{RESUMO}

Objetivo: Analisar as produções científicas acerca da notificação de violência contra adolescente. Métodos: Tratou-se de estudo de revisão da literatura, realizado no período de setembro a outubro de 2013. Foram incluídos os artigos publicados entre 2003 e 2013; pesquisas realizadas no Brasil; nos idiomas inglês, espanhol e português; indexados nas bases de dados Literatura Latino-Americana e do Caribe em Ciências da Saúde (LILACS), Medical Literature Analysis and Retrieval System Online (MEDLINE) e Scientific Electronic Library Online (SciELO), combinando os seguintes descritores: violência, notificação de abuso, defesa da criança e do adolescente, notificação, adolescente. Resultados: A pesquisa resultou em 10 artigos, dos quais se destacaram três eixos temáticos: seis abordavam "caracterização dos casos de violência", sete descreviam "o profissional como um atuante na notificação" e cinco discutiam "qualidade da notificação e registros de violência". Conclusão: A caracterização da violência, o conhecimento da equipe de saúde e a subnotificação vêm sendo abordados com muita pertinência, sendo estes temas fundamentais para melhorar tanto a qualidade quanto a quantidade da notificação.

Descritores: Notificação; Violência; Vigilância Epidemiológica.

\section{ABSTRACT}

Objective: To analyse the scientific production regarding notification of violence against adolescent. Methods: This is a literature review study, conducted in the period between September and October 2013. It included the articles published between 2003 and 2013; researches conducted in Brazil; in English, Spanish, and Portuguese; indexed in LatinAmerican and Caribbean System on Health Sciences Information (LILACS), Medical Literature Analysis and Retrieval System Online (MEDLINE) and Scientific Electronic Library Online (SciELO) databases. Combining the descriptors (Violence, Abuse Registry; Defense of Children and Adolescents; Notification; Adolescents). Results: The research found 10 articles, where three main themes were highlighted: 06 addressed the 'characterization of cases of violence'; 07 described 'the professional as an active tart in the notification', and 05 discussed the 'quality of the notification and violence registries'. Conclusion: The violence characterization, the health team's knowledge, and underreporting have been addressed with great relevance and such themes are key to improving both the quality and the quantity of the notification.

Descriptors: Notification; Violence; Epidemiological Surveillance.

1) Universidade de Pernambuco - UPE Recife (PE) - Brasil

\author{
Taciana Mirella Batista dos \\ Santos $^{(1)}$ \\ Tarcísia Domingo de Araujo \\ Sousa $^{(1)}$ \\ Grizielle Sandrine de Araujo \\ $\operatorname{Rocha}^{(1)}$ \\ Lygia Maria Pereira da Silva ${ }^{(1)}$
}

Recebido em: 22/12/2013 Revisado em: 12/02/12014 Aceito em: 21/08/2014 


\section{RESUMEN}

Objetivo: Analizar las producciones cientificas sobre la notificación de violencia contra adolescentes. Métodos: Se trató de un estudio de revisión de literatura realizado entre septiembre y octubre de 2013. Se incluyó los artículos publicados entre 2003 y 2013; investigaciones realizadas en Brasil; en los idiomas inglés, español y portugués en las bases de datos Literatura LatinoAmericana de Ciências da Saúde (LILACS), Medical Literature Analysis and Retrieval System Online (MEDLINE) y Scientific Eletronic Library Online (SciELO), asociando los descriptores violencia, notificación de abuso, defensa del niño y del adolescente, notificación, adolescente. Resultados: La investigación resultó en 10 artículos de los cuales se destacaron cuatro ejes temáticos: seis abordaron "caracterización de los casos de violencia" siete describieron "el profesional como actuante en la notificación" y cinco discutieron "calidad de la notificación y registros de violencia”. Conclusión: La caracterización de la violencia, el conocimiento del equipo de salud y la subnotificación han sido abordados con mucha pertinencia siendo estos temas fundamentales para mejorar la calidad y cantidad de la notificación.

Descriptores: Notificación; Violencia; Vigilancia Epidemiológica.

\section{INTRODUÇÃO}

Em consonância com o que dispõe o Estatuto da Criança e do Adolescente (ECA), adolescentes são indivíduos com idade cronológica entre doze e dezoito anos de idade. No Brasil, durante muito tempo, a violência contra crianças e adolescentes passou despercebida pela comunidade científica e pela Justiça. Hoje, ela é considerada um problema de saúde pública, passando a ter relevância no meio científico ${ }^{(1)}$.

Segundo o Censo Demográfico de 2010, os jovens entre 12 e 18 anos de idade somam 24.033 .745 de brasileiros, o que corresponde a $12,6 \%$ da população total ${ }^{(2)}$.

O Mapa da Violência aborda uma análise internacional sobre o número de homicídios de crianças com até quatro anos de idade, na qual o Brasil ocupava a $23^{\text {a }}$ posição. Ao se avaliar as idades entre 15 e 19 anos, o Brasil assumiu a $4^{\mathrm{a}}$ posição, dado que revela a violência como um problema que atinge principalmente essa faixa etária. Os estados com os maiores números de registros de violência contra adolescentes nessa faixa etária foram Amapá, Alagoas e Bahia, respectivamente. Rondônia e Espírito Santo apresentaram os menores índices do país ${ }^{(3)}$.

Para o Estado, essa relevância ocorreu após a promulgação do ECA, o qual veio assegurar direitos especiais e proteção integral a essa população, além da obrigatoriedade da notificação compulsória ${ }^{(4)}$. Esse instrumento define legalmente as normas de conduta aos profissionais de saúde, tornando obrigatória a notificação de violência e maus-tratos (artigos, 13 e 245), seja de casos suspeitos ou confirmados ${ }^{(1)}$.

A violência constitui um grande problema, pois, além do significativo número de agravos e mortes que geram um forte impacto nos índices de mortalidade e morbidade, as causas externas são responsáveis por uma perda social e econômica, caracterizada por uma enorme quantidade de seqüelas, gastos hospitalares e previdenciários, além de causar intenso sofrimento às famílias dos vitimizados ${ }^{(5)}$.

O crescimento dos óbitos por causas externas, incluindo a violência, entre os mais jovens vem aumentando nas últimas décadas. Em 1980, era responsável por 6,7\% dos óbitos; em 2010, obteve o impressionante número de $26,5 \%$ - um aumento de $19,8 \%$ em apenas três décadas. É a primeira causa de morte entre a faixa etária de 1 a 19 anos, seguida pelas neoplasias e tumores, com $7,8 \%$, e pelas doenças do aparelho respiratório, com $6,6 \%{ }^{(3)}$.

O termo "notificação da violência" é bastante conhecido na área da saúde, enquanto o termo "comunicação da violência" é usado em outras áreas ${ }^{(6)}$. Os profissionais da saúde, ao realizarem o preenchimento da ficha de notificação, devem encaminhar uma das vias para a vigilância epidemiológica das Secretarias Municipais de Saúde. Essa ficha fornece dados a serem computados no Sistema de Informação de Agravos de Notificação (SINAN). Uma cópia deve ficar na unidade de saúde que notificou a violência, enquanto a terceira cópia deve ser encaminhada ao Conselho Tutelar ou às autoridades competentes (Art.13 da Lei $n^{\circ} 8.069 / 1990$ ), alertando que aquele adolescente, ou a família deste, necessitam de ajuda ${ }^{(7)}$.

Os casos de violência notificados no Brasil totalizam 157.370 em 2012 - em 2013, até o mês de julho, já somavam 70.669. Destes, 17.538 casos foram notificados em adolescentes de 10 a 19 anos. Sendo a violência física $(65,3 \%)$ a mais notificada, e o principal agressor identificado era conhecido da vítima ${ }^{(8)}$.

O Ministério da Saúde (MS), reconhecendo a inclusão da violência nesse setor, assim como a obrigatoriedade da notificação desse agravo, implantou em 2006 um sistema de Vigilância de Violências e Acidentes (VIVA), cujo objetivo é identificar e divulgar dados de violência e acidentes no Brasi $1^{(9)}$. Portanto, o MS depende da notificação da violência para conhecer o perfil e monitorar os casos de violência no âmbito da vigilância epidemiológica ${ }^{(10)}$.

Mesmo após a promulgação do ECA, a inserção da violência na lista de agravos de notificação compulsão, a criação do VIVA e outras medidas de prevenção contra a violência e proteção aos adolescentes, percebe-se que esses mecanismos ainda são insuficientes para lidar com essa temática ${ }^{(11)}$. Constituindo uma parcela maior, estão os 
casos não notificados, referentes à "violência silenciosa", não aparecendo por falta de notificação e cobertura dos serviços. Diante das subnotificações e da imprecisão no total dos casos notificados de violência ainda não se conhece a verdadeira realidade da violência contra o adolescente ${ }^{(12)}$.

Uma das diretrizes propostas pela Organização Mundial de Saúde (OMS) é a melhoria e o desenvolvimento no setor de informações ${ }^{(13)}$. A secretaria de vigilância à saúde, desde 2005, vem tentando capacitar profissionais de várias áreas e das diversas regiões do país, na intenção de melhorar a qualidade dos registros $^{(8)}$, assim como é importante pensar em estratégias e parcerias visando à proteção da vítima e o apoio familiar ${ }^{(14)}$.

Embora nessas últimas décadas tenha ocorrido maior visibilidade da violência contra o adolescente, seja no âmbito da saúde, das políticas públicas ou no meio acadêmico, muito ainda resta a investigar, na busca da compreensão sobre a violência, em sua complexidade, e os fatores que a cercam ${ }^{(11)}$. A notificação tem um papel fundamental, seja na proteção do adolescente através da comunicação ao conselho tutelar, ou na visibilidade desse problema, por meio da comunicação à vigilância epidemiológica.

Diante da relevância desse tema, assim como para compreendê-lo melhor, é necessário conhecer a discussão dessa temática no meio acadêmico. Por isso, este trabalho teve como objetivo analisar as produções científicas acerca da notificação de violência contra adolescente.

\section{MÉTODOS}

Tratou-se de estudo de revisão da literatura, realizado entre setembro e outubro de 2013. Para a elaboração da pesquisa, foram seguidas as seguintes etapas: identificação do tema; estabelecimento de critérios para a inclusão e exclusão dos artigos selecionados; definição das características das pesquisas primárias; avaliação dos artigos incluídos; interpretação dos resultados; e apresentação da revisão, proporcionando um exame crítico dos achados ${ }^{(15)}$.

Os artigos obedeceram a estes critérios de inclusão: período de publicação entre 2003 e 2013; realizados no Brasil; redigido nos idiomas português, espanhol e inglês; indexados nas bases de dados da Biblioteca Virtual em Saúde (Literatura Latino-Americana de Ciências da Saúde (LILACS), Medical Literature Analysis and Retrieval System Online (MEDLINE) e na biblioteca virtual Scientific Eletronic Library Online (SciELO).

O processo de busca dos artigos deu-se pela combinação destes descritores: violência; notificação de abuso; defesa da criança e do adolescente; notificação; e adolescente, estabelecendo os filtros de acordo com os critérios de inclusão e exclusão. Após a leitura dos títulos e resumos, excluíram-se os artigos inapropriados para a temática abordada e os artigos repetidos, encontrados a partir dos cruzamentos dos descritores.

Dez artigos compuseram a amostra (Figura 1). A leitura minuciosa possibilitou extrair as seguintes informações: autores, ano de publicação, periódico de publicação, tipo de estudo, objetivos, características da amostra e metodologia. Os dados foram analisados por meio da análise do conteúdo $^{(16)}$, que é composta por fases, nesta ordem cronológica: 1) pré-análise dos dados obtidos, tendo por objetivo operacionalizar as ideias iniciais sobre o tema; 2 ) exploração do material, tornando as características do texto claras ao pesquisador, gerando unidades de significação agregadas; e 3) tratamento e interpretação dos resultados, em que os dados serão realmente tratados de maneira a tornarem-se significativos.

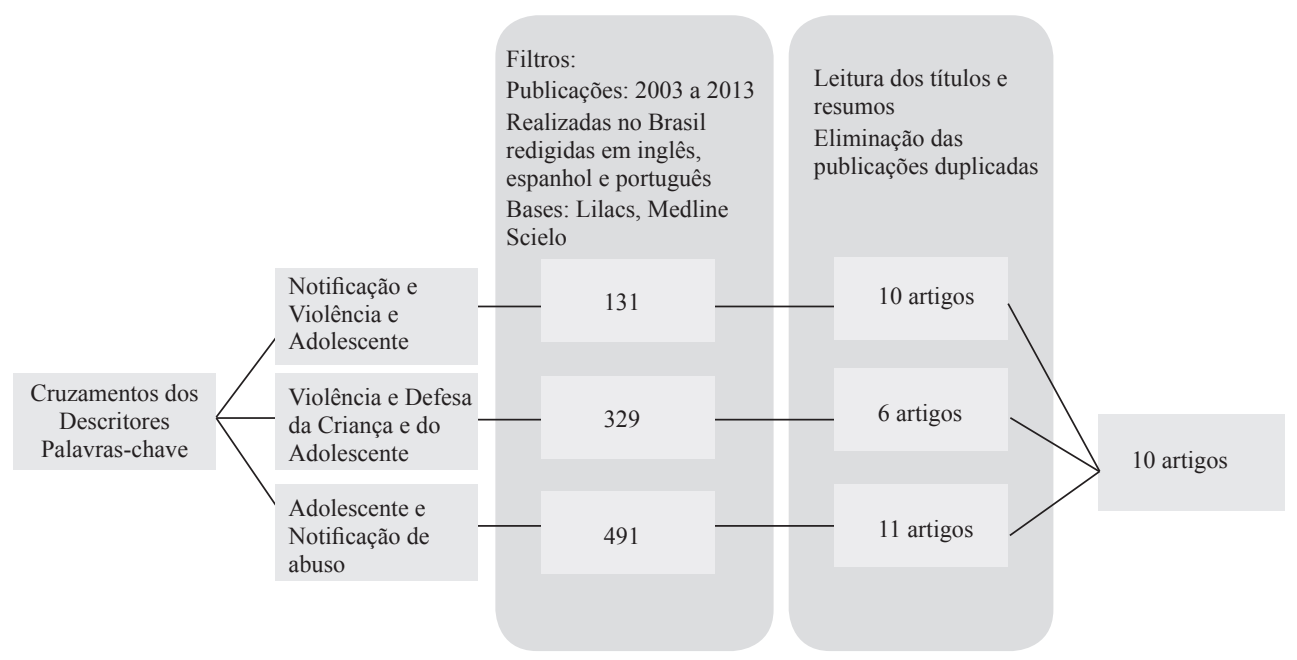

Figura 1 - Distribuição e seleção dos artigos segundos os critérios de elegibilidade estabelecidos na pesquisa (Set-Out, 2013). 
Dessa análise, emergiram três categorias: "caracterização dos casos de violência"; "o profissional como um atuante na notificação" e "qualidade da notificação e registros de violência". A revisão foi realizada por pares, como forma de minimizar a subjetividade na seleção dos artigos.

\section{RESULTADOS}

Dos trabalhos selecionados, seis tiveram como objetivo a caracterização dos casos de violência ${ }^{(6,10,11,17,18,19)}$ - destes, dois tinham foco ${ }^{(11,17)}$ apenas os adolescentes. O tema da prática profissional como um atuante na notificação

Quadro I - Caracterização dos artigos incluídos para na revisão segundo autores, ano, amostra, delineamento da pesquisa e objetivo (Set-Out, 2013).

\begin{tabular}{|c|c|c|c|}
\hline Autor/Ano & Amostra & Delineamento da Pesquisa & Objetivo das Produções \\
\hline $\operatorname{Costa}^{(17)}(2007)$ & $\begin{array}{l}\mathrm{n}=1.156 \text { casos de } \\
\text { violência }\end{array}$ & Transversal, Documental & $\begin{array}{l}\text { Estimar a prevalência das formas de violência contra } \\
\text { crianças e adolescentes, registradas nos Conselhos } \\
\text { Tutelares, e a associação dessas violências por faixas } \\
\text { etárias das vítimas e vínculo com agressores, em } \\
\text { 2003-2004; }\end{array}$ \\
\hline $\begin{array}{l}\text { Banzon }^{(18)} \\
(2008)\end{array}$ & $\begin{array}{l}\mathrm{n}=7.765 \text { fichas de } \\
\text { notificação }\end{array}$ & $\begin{array}{c}\text { Quantitativo, Qualitativo, } \\
\text { Documental }\end{array}$ & $\begin{array}{l}\text { Discutir o sistema conceitual de classificação } \\
\text { das diferentes violências dirigidas à infância e a } \\
\text { adolescência; }\end{array}$ \\
\hline $\begin{array}{l}\text { Martins }^{(19)} \\
(2009)\end{array}$ & $\begin{array}{l}\mathrm{n}=308 \text { notificações } \\
\text { por negligência e } \\
\text { abandono }\end{array}$ & $\begin{array}{c}\text { Transversal, Descritivo, } \\
\text { Documental }\end{array}$ & $\begin{array}{l}\text { Analisar as características da negligência/abandono } \\
\text { contra menores de } 15 \text { anos residentes em Londrina, } \\
\text { PR, cujo evento foi notificado aos Conselhos } \\
\text { Tutelares e serviços de atendimento, em 2006; }\end{array}$ \\
\hline $\operatorname{Luna}^{(20)}(2010)$ & $\begin{array}{l}\mathrm{n}=359 \\
\text { profissionais } \\
\text { do programa } \\
\text { Estratégia Saúde } \\
\text { da Família }\end{array}$ & Quantitativo, Transversal & $\begin{array}{l}\text { Analisar o processo de notificação de maus-tratos em } \\
\text { crianças e adolescentes por profissionais da Equipe } \\
\text { Saúde da Família; }\end{array}$ \\
\hline Silva $^{(21)}(2011)$ & $\mathrm{n}=31$ publicações & Revisão de Literatura & $\begin{array}{l}\text { Refletir sobre a violência sexual contra crianças e } \\
\text { adolescentes, focalizando a atuação do enfermeiro } \\
\text { à luz da sua prática profissional e da legislação } \\
\text { brasileira; }\end{array}$ \\
\hline $\operatorname{Lima}^{(6)}(2011)$ & $\begin{array}{l}\mathrm{n}=184 \text { documentos } \\
(27 \text { artigos, } 1 \\
\text { dissertação, } 1 \text { tese) }\end{array}$ & $\begin{array}{l}\text { Estudo comparativo e } \\
\text { documental através de } \\
\text { leis, portarias, normativas } \\
\text { e pesquisa bibliográfica } \\
\text { complementar }\end{array}$ & $\begin{array}{l}\text { Caracterizar o contexto histórico de enfrentamento } \\
\text { da violência sexual contra crianças e adolescentes, } \\
\text { e o seu processo de notificação, no Brasil e nos } \\
\text { Estados Unidos (EUA); Estabelecer parâmetros de } \\
\text { comparação entre a realidade brasileira e americana; }\end{array}$ \\
\hline $\begin{array}{l}\text { Justino( }^{(22)} \\
(2011)\end{array}$ & $\begin{array}{l}\mathrm{n}=361 \text { casos } \\
\text { notificados ao } \\
\text { Conselho Tutelar }\end{array}$ & $\begin{array}{l}\text { Quantitativo, Descritivo } \\
\text { Retrospectivo, Documental }\end{array}$ & $\begin{array}{l}\text { Verificar nos Conselhos Tutelares Norte e Sul do } \\
\text { município de Campo Grande, Mato Grosso do Sul, a } \\
\text { ocorrência de notificações de violência sexual contra } \\
\text { adolescentes (2007-2008). }\end{array}$ \\
\hline $\begin{array}{l}\text { Pordeus } \\
(2011)\end{array}$ & $\begin{array}{l}\mathrm{n}=82.175 \text { fichas de } \\
\text { denúncia }\end{array}$ & Quantitativo, Descritivo & $\begin{array}{l}\text { Analisar as denúncias de direitos violados das } \\
\text { crianças e adolescentes; recebidas elos Conselhos } \\
\text { Tutelares na região nordestina (2002-2007); }\end{array}$ \\
\hline $\begin{array}{l}\text { Oliveira }^{(11)} \\
\text { (2011) }\end{array}$ & $\begin{array}{l}\mathrm{n}=333 \\
\text { adolescentes } \\
\text { atendidos no } \\
\text { ambulatório }\end{array}$ & Transversal, Documental & $\begin{array}{l}\text { Estimar o sub-registro da violência doméstica em um } \\
\text { serviço de atenção a adolescentes (10 a } 19 \text { anos) no } \\
\text { Recife/PE; }\end{array}$ \\
\hline $\begin{array}{l}\text { Velosso }^{(10)} \\
(2013)\end{array}$ & $\begin{array}{l}\mathrm{n}=3.267 \\
\text { notificações }\end{array}$ & Transversal, Documental & $\begin{array}{l}\text { Caracterizar a ocorrência de violência doméstica, } \\
\text { sexual e de outras, a partir das informações do banco } \\
\text { de dados do Sistema Informação de Agravos de } \\
\text { Notificação (SINAN) }\end{array}$ \\
\hline
\end{tabular}


apresentou sete produções ${ }^{(6,11,19,20,21,22,23)}$, das quais cinco tiveram como objetivo a caracterização, descrição ou qualidade da notificação e registros de violência ${ }^{(6,11,21,22,23)}$, sendo este seu objetivo principal ou não (Quadro I).

\section{DISCUSSÃO}

Com o intuito de facilitar o entendimento da discussão da literatura levantada e se compreender de forma acurada a notificação sobre violência contra adolescentes, optou-se pela sistematização do conhecimento em eixos temáticos, de acordo com a similaridade de seus conteúdos.

\section{Caracterização da violência}

Os estudos de prevalência mostram que os adolescentes ainda são grandes vítimas da violência ${ }^{(10)}$. Se por vezes as crianças são as principais vítimas, por outras estão no mesmo patamar as crianças e os adolescentes ${ }^{(20)}$, o que reafirma que esse grupo encontra-se em situação de vulnerabilidade frente à violência. $\mathrm{O}$ agressor mais notificado foi do sexo masculino, muitas vezes conhecido ou responsável pela vítima $^{(10,17)}$. No entanto, nos casos de negligência, a mãe foi a maior perpetradora da violência ${ }^{(17,18,21)}$. A residência da vítima foi o local mais notificado como sendo o local da agressão ${ }^{(17,21)}$, enquanto em um trabalho realizado em Belém-PA, a via pública foi o local de maior ocorrência de violência, segundo as notificações realizadas ${ }^{(10)}$.

Com relação à violência doméstica, as garotas na faixa etária entre 15 e 19 anos são as principais vítimas desse tipo de violência, mesmo a vítima possuindo alguma ocupação (trabalho/escola) ou morando com os pais e não possuindo vícios $^{(17,19)}$. Em estudo feito com crianças e adolescentes em 2007, a principal queixa de violência foi o espancamento. Nos primeiros anos da adolescência, os jovens são agredidos da mesma forma pelo pai e pela mãe, enquanto os adolescentes com mais idade sofrem punições mais severas, sobretudo do pai. Vale salientar que, nesses casos, a punição paterna se diferencia da punição materna na intensidade e gravidade das lesões ${ }^{(21)}$.

Esses achados corroboram com outro estudo realizado no Nordeste, o qual encontrou o pai e o padrasto como os principais violadores de direito dos adolescentes ${ }^{(20)}$, o que pode ser reflexo de uma cultura patriarcal. Na tentativa de imposição do poder, os perpetradores fazem uso da força física, coisificando os adolescentes ${ }^{(21)}$.

A violência física praticada pelos pais costuma estar relacionada à mudança no comportamento dos adolescentes e também pode estar relacionada à fragilidade dos vínculos afetivos, podendo tais vínculos estarem prejudicados desde a infância, apresentando consequências como rejeição entre pais e filhos na adolescência ${ }^{(21)}$.
Para muitos, a família é a "base de tudo". No senso comum, é sinônimo de afeto, educação e proteção. No entanto, esse conceito previamente formado vem mudando devido às várias denúncias de violência que ocorrem dentro da própria família ${ }^{(24)}$. O excesso nos castigos praticados pelos pais é bastante discutido pelas diversas áreas que estudam a temática. A violência doméstica contra crianças e adolescentes, algumas vezes, é a representação do abuso do "poder disciplinar" dos pais e responsáveis, reduzindo a vítima à condição de objeto de maus-tratos ${ }^{(24)}$. Por ser o lar o local de maior ocorrência da violência, é sensato discutir a família como alvo de intervenção ${ }^{(18)}$.

Com relação à violência sexual, os estudos afirmam que as adolescentes estão entre as principais vítimas ${ }^{(21)}$. Esse tipo de violência tem como principal agressor alguém conhecido da vítima - geralmente, o pai ou o padrasto. $\mathrm{O}$ fato de o perpetrador da violência sexual ser um parente da vítima leva muitas vezes a não denúncia dos casos, pois caso a vítima tente fazer a denúncia, ela pode ser coagida pelo agressor ou por outros familiares. Outros membros da família optam por não denunciar, para preservar a família, e fecham os olhos para as vitimas ${ }^{(17)}$.

Enquanto um estudo realizado no Nordeste refere que as notificações diminuíram entre 2002 e 2007(20), um estudo realizado no estado do Pará encontrou que, entre os anos de 2009 e 2011, o número de casos notificados teve um aumento de 80,1\%. O aumento não é o suficiente para afirmar que houve aumento da violência. Ele representa o desempenho dos profissionais na identificação dos casos, após um curso de capacitação oferecido à rede pública ${ }^{(10)}$.

$\mathrm{O}$ estudo da violência deve ser analisado no contexto em que o fenômeno ocorre. Destarte, ajuda a compreender que as informações conhecidas não representam a realidade, mas revelam as características da violência mais notificada. A violência psicológica, assim como a negligência ${ }^{(18)}$, por não deixar marcas de agressão física, torna-se de difícil identificação e notificação, colaborando com a cronicidade do fato e levando os adolescentes a um sofrimento mental que pode acarretar em prejuízos no desenvolvimento psicossocial, afetivo e cognitivo ${ }^{(25)}$. Os adolescentes também sofrem humilhações nas ruas, ameaças de morte e tornam-se amedrontados, o que também caracteriza a violência psicológica ${ }^{(21)}$.

Há uma escassez de artigos sobre violência que abordem projetos de intervenção, tanto com os profissionais quanto com os adolescentes. Essa lacuna pode ser estreitada a partir do reconhecimento da violência como um problema de saúde publica. Caracterizar o perfil da violência foi o primeiro passo, mas, diante desse conhecimento, é necessário investir para encontrar soluções possíveis, com o objetivo de promover a cultura de paz e reduzir o número de vítimas de violência. 


\section{Os profissionais que notificam a violência}

A notificação da violência, mesmo obrigatória, sofre interferência do profissional que a faz. Por isso, uma das temáticas que emergiram da leitura desses artigos foi a relação do profissional com a violência e os fatores que dificultam ou facilitam a notificação dos casos.

Os profissionais temem o envolvimento em casos de violência, por medo de represália por parte do agressor e da comunidade, além de acarretar demandas judiciais, como a convocação para prestar depoimento diante do caso assistido pelo profissional ${ }^{(23)}$. Também passa a vivenciar constantemente um dilema ético diante da situação em que o princípio da integridade familiar se contrapõe ao princípio dos melhores interesses do adolescente ${ }^{(24)}$.

A resistência à notificação pode ser superada com estratégias que criem condições de segurança para a prática profissional. Uma proposta a ser considerada é o compartilhamento da responsabilidade entre os profissionais que realizam o atendimento, tendo o gestor como notificante, deixando de expor um único profissional ${ }^{(19,22)}$.

A instituição de saúde é, por diversas vezes, a porta de entrada para a assistência às vítimas de violência, por isso, esses profissionais precisam estar devidamente qualificados, tendo em vista que eles também têm a função de proteger e preservar o direito do adolescente ${ }^{(18,22)}$.

Reconhecendo a importância do profissional da saúde no enfrentamento da violência e as dificuldades enfrentadas por esse grupo é que se faz necessário maior investimento nos recursos humanos, de tal modo que a notificação seja feita com maior frequência, segurança e melhor qualidade ${ }^{(19)}$. Ainda na perspectiva de melhorar a qualificação profissional, os autores ressaltam a incorporação da temática da violência nas diretrizes curriculares, para a construção de um perfil acadêmico e profissional com competências, habilidades e conteúdos ${ }^{(19,22)}$.

A violência sexual é um dos graves problemas de saúde pública $^{(17)}$ e parece ser a que mais sensibiliza os profissionais da saúde. No entanto, exige uma ação multiprofissional, consistindo num desafio para o setor da saúde, tendo em vista a necessidade de mudança de paradigma para o enfrentamento do problema ${ }^{(19)}$.

Os estudos propõem atividades e ações educativas junto às famílias, devendo ser desenvolvidas em todos os níveis de complexidade (primária, secundária e terciária), de forma preventiva. Eles têm como público-alvo os pais e abordam os direitos das crianças e dos adolescentes de crescerem sem violência e os efeitos desta para a saúde da vítima, buscando adesão ao tratamento dos agravos resultantes da violência e esclarecendo sobre os deveres dos adultos responsáveis em relação à segurança e ao bemestar das crianças. Tudo isso para fortalecer e estruturar as famílias, pois são elas que primeiramente desempenham o papel de proteger as crianças e os adolescentes ${ }^{(18,19)}$.

Um local que disponibilize e assegure serviços de uma equipe interdisciplinar, com apoio médico, psicológico, social e jurídico, é necessário a todos os envolvidos no problema. E a partir desse trabalho humanizado e integrado é que acontecem os encaminhamentos das vítimas, no intuito de fortalecer a rede de proteção ${ }^{(18)}$.

Os artigos reforçam o setor saúde com a obrigatoriedade da notificação, por meio da lei federal, a Portaria $\mathrm{n}^{\mathrm{o}}$ $1.968 / 2001 \mathrm{MS}^{(10,19)}$. E alguns ressaltaram, especificamente, o Código de Ética de Enfermagem como dever profissional de proteção aos seus clientes em situações de risco e agravos, valorizado e considerado um dever do(a) enfermeiro(a) diante da equipe de saúde ${ }^{(12,17,19)}$. A atuação da enfermagem é percebida como ampla e complexa, ressaltando que o ato de notificar não encerra a atuação do enfermeiro na atenção às vítimas que continuarão precisando de acompanhamento ${ }^{(19)}$. Além disso, compete ao profissional de enfermagem, além dos demais profissionais de saúde, desde a atenção de baixa complexidade na identificação de famílias com risco potencial, para comportamentos abusivos, até a atenção de alta complexidade, com a participação no diagnóstico, no tratamento dos agravos resultantes da violência, nas ações educativas e, principalmente, na notificação ${ }^{(17,19)}$.

Os profissionais de saúde não podem ficar alheios a essa problemática $^{(17)}$; eles devem se reconhecer e inserir-se nessa temática ${ }^{(19)}$. Um estudo realizado em Londrina-PR revela que a tipologia da violência mais notificada pelos profissionais de saúde são a negligência e o abandono, o que pode estar relacionado com o estado geral de saúde da vítima com a necessidade de assistência, como vítimas de lesões de pele por má higiene corporal, desnutrição, calendário vacinal desatualizado e reincidência de internações por tratamentos inadequados. Não obstante, os profissionais reconhecem as dificuldades em identificar o que realmente é violência quando esta não está sob a forma de lesão física ${ }^{(10,18)}$.

Estudos que fizeram referência às habilidades, competências e sensibilidades dos profissionais da saúde revelaram a necessidade de melhorar a assistência e aperfeiçoar a qualidade da notificação, evitando que os casos passem despercebidos pela equipe de saúde. Esses profissionais não podem ficar alheios à problemática da violência contra os adolescentes. O preparo dos profissionais e a qualidade da assistência das instituições de saúde para atuarem com a população infanto-juvenil vêm ganhando destaque na literatura científica.

\section{Subnotificação da violência}

Os registros de violência não são notificados em um banco de dados único, pois existem vários locais onde 
se podem investigar tais registros. Esse fato dificulta a precisão no número de notificações. Além disso, muitos casos não chegam a ser notificados, por isso pesquisadores afirmam que, devido à subnotificação, o que se sabe sobre a violência é a ponta do iceberg ${ }^{(3)}$.

O Conselho Tutelar deveria ser o principal lócus de informação para o delineamento de dados gerados sobre as formas de violência, pois, levando-se em conta o ECA, tal órgão deveria se configurar, ainda que potencialmente, em espaço de convergência de informações referentes às diversas situações vividas pelas crianças e adolescentes. Considerando-se que todos os casos suspeitos e/ou comprovados de ameaça ou violação de seus direitos devem ser notificados nessa instância ${ }^{(22,23)}$.

É interessante ressaltar as particularidades de cada tipo de violência. Alguns autores revelam, assim, diferentes motivos para subnotificação. A violência sexual parece ter o registro extremamente complicado, visto que se constitui um evento no qual há marca registrada, um "pacto de silêncio". Na maioria das vezes, as vítimas deixam de buscar atendimento, dado o temor de represálias, o preconceito e a vergonha - fatores que dificultam o relato dos acontecimentos, particularmente no caso de adolescentes $^{(17)}$.

Outra situação identificada pelos autores é a falta de preparo e a insensibilidade de alguns profissionais no atendimento às vítimas em delegacias, hospitais e conselhos tutelares. Fato que agrava a situação da subnotificação ou notificação com dados incompletos, prejudicando a investigação e a tomada de decisões pelas autoridades responsáveis ${ }^{(10,17)}$

No caso da negligência e abandono, mesmo sendo esta uma das formas mais frequentes de violência e maus-tratos e, desde 2001, um agravo de notificação compulsória em todo o território nacional ${ }^{(23)}$, encontram-se fortes indícios de subnotificação, devido ao desconforto e ao despreparo dos profissionais de saúde em identificar e manejar os casos, pois os sinais produzidos podem ser mais subjetivos do que as lesões deixadas pela agressão física ${ }^{(10,22,23)}$.

Ainda sobre maus-tratos, estudos apontam que, além das dificuldades encontradas pelos profissionais de saúde e outros que lidam com as vítimas nessa situação, outro dificultador das notificações é a própria família. Os familiares podem negar informações que fundamentem as suspeitas e produzir relatos falsos para mascarar a situação ${ }^{(10,22)}$. Quando se trata de violência intrafamiliar, geralmente os denunciantes são vizinhos ou conhecidos e não querem se envolver, por isso fornecem dados incompletos ou optam pelo anonimato ${ }^{(20)}$.

Além disso, há dificuldades estruturais dos serviços públicos, como a dificuldade para o funcionamento dos conselhos tutelares, e até a inexistência destes em alguns municípios brasileiros, precariedade dos serviços de retaguarda para executar as medidas aplicadas, a forma heterogênea dos conselheiros e a grande demanda de serviços enfrentadas por esses órgãos ${ }^{(18)}$.

Dentre algumas limitações desta revisão, pode-se citar o fato de os artigos apresentarem faixas etárias diferentes para adolescentes e crianças. Por isso, é interessante que as pesquisas realizadas com esses grupos adotem um conceito já estabelecido.

\section{CONCLUSÃO}

A caracterização da violência, o conhecimento da equipe de saúde e a subnotificação vêm sendo abordados com muita pertinência, sendo estes temas fundamentais para melhorar tanto a qualidade quanto a quantidade da notificação.

\section{REFERÊNCIAS}

1. Estatuto da Criança e do Adolescente - ECA. Lei Federal no ${ }^{\circ}$ 8.069, de 13/07/1990.15 [acesso em 2014 Dez 15]. Disponível em: http://www.planalto.gov.br/ ccivil 03/leis/18069.htm

2. Instituto Brasileiro de Geografia e Estatística - IBGE. Censo Demográfico 2010. Brasília: IBGE; 2010.

3. Waiselfisz JJ, Centro Brasileiro de Estudos LatinoAmericanos - CEBELA. Mapa da violência 2012: crianças e adolescentes do Brasil. $1^{\mathrm{a}}$ ed. Rio de Janeiro: Flasco Brasil; 2012.

4. Barbosa LV, Soares ACGM, Cruz KV, Silva RA. Caracterização da violência sexual em criança no município de Aracaju/SE. Interf Científicas Saúde Ambiente. 2013;1(2):9-20.

5. Macedo LR, Macedo MR, Silva CR, Macedo CR. Acidentes por causas externas em crianças e adolescentes do Espírito Santo, Brasil. Rev Bras Pesqui Saúde. 2011;13(4):41-7.

6. Lima JS, Deslandes SF. A notificação compulsória do abuso sexual contra crianças e adolescentes: uma comparação entre os dispositivos americanos e brasileiros. Interface (Botucatu). 2011;15(38):819-32.

7. Ministério da Saúde (BR), Secretaria de Vigilância em Saúde, Departamento de Vigilância Epidemiológica. Sistema de Informação de Agravos de Notificação Sinan: normas e rotinas. Brasília: Ministério da Saúde; 2006.

8. Ministério da Saúde (BR). DATASUS. Violência doméstica, sexual e/ou outras violências - SINAN: 
2009- 2014 [acesso em 2014 Dez 15]. Disponível em: http://dtr2004.saude.gov.br/sinanweb/tabnet/ dh?sinannet/violencia/bases/violebrnet.def

9. Ministério da Saúde (BR). Impacto da violência na saúde nas crianças e adolescentes/ Prevenção de violência e promoção da cultura de paz: você é a peça principal para enfrentar este problema. Brasília: Ministério da Saúde; 2009.

10. Veloso MMX, Magalhães CMC, Dell'Aglio DD, Cabral IR, Gomes MM. Notificação da violência como estratégia de vigilância em saúde: perfil de uma metrópole do Brasil. Ciênc Saúde Coletiva. 2013;18(5):1263-72.

11. Oliveira MTD, Lima MLCD, Barros MDDA, Paz AM, Barbosa AMF, Leite RMB. Sub-registro da violência doméstica em adolescentes: a (in) visibilidade na demanda ambulatorial de um serviço de saúde no Recife-PE, Brasil. Rev Bras Saúde Matern Infant. 2011;11(1):29-39.

12. Zanatta EA, Pai DD, Resta DG, Argenta C, Motta MDGC. Caracterização das notificações de violência contra adolescentes. Enferm Foco (Brasília). 2012;3(4):165-8.

13. Minayo MCS. Violência e saúde. Rio de Janeiro: Editora Fiocruz; 2006.

14. Cocco M, Silva EB, AC Jahn. Abordagem dos profissionais de saúde em instituições hospitalares a crianças e adolescentes vítimas de violência. Rev Eletrônica Enferm. 2010;12(3):491-7.

15. Mendes KDS, Silveira RCCP, Galvão CM. Revisão integrativa: método de pesquisa para incorporação de evidências na saúde e na enfermagem. Texto \& Contexto Enferm. 2008;17(4):758-64.

16. Bardin L. Análise do Conteúdo. Lisboa: Edições 70; 2007.

17. Justino LCL, Ferreira SRP, Nunes CB, Barbosa MAM, Gerk MAS, Freitas SLF. Violência sexual contra adolescentes: notificações nos conselhos tutelares, Campo Grande, Mato Grosso do Sul, Brasil. Rev Gaúch Enferm. 2011;32(4):781-7.

18. Martins CBG, Jorge MHPM. Negligência e abandono de crianças e adolescentes: análise dos casos notificados em município do Paraná, Brasil. Pediatria (São Paulo). 2009;31(3):186-97.
19. Silva LMP, Carvalho Ferriani MDG, Silva MAI. Atuação da enfermagem frente à violência sexual contra crianças e adolescentes. Rev Bras Enferm. 2011;64(5):919-24.

20. Pordeus AMJ, Souza Vieira LJE, Luna GLM, Albuquerque IRR, Moreira DP, Frota MA, et al. Notificação de direitos violados segundo o Sistema de Informação par a Infância e Adolescência (SIPIA) no Nordeste brasileiro. Rev Bras Promoç Saúde. 2011;24(4):313-21.

21. Costa MCO, Carvalho RCD, Bárbara JFRS, Santos CAST, Gomes WDA, Sousa HLD. O perfil da violência contra crianças e adolescentes, segundo registros de Conselhos Tutelares: vítimas, agressores e manifestações de violência. Ciênc Saúde Coletiva. 2007;12(5):1129-41.

22. Luna GLM, Parente EO, Moreira DP, Vieira LJES. Notificação de maus-tratos contra crianças e adolescentes: o discurso oficial e a práxis Rev Enferm UERJ. 2010; 18(1):148-52.

23. Bazon MR. Violências contra crianças e adolescentes: análise de quatro anos de notificações feitas ao Conselho Tutelar na cidade de Ribeirão Preto, São Paulo, Brasil. Cad Saúde Pública. 2008;24(2):323-32.

24. Rizzini I. Para além da centralidade da família. Psicologia: Ciência e Profissão. 2010; 7(7):20-22.

25. Ministério da Saúde (BR). Impacto da violência na saúde das crianças e adolescentes. Brasília: Ministério da Saúde; 2008.

\section{Endereço do primeiro autor:}

Taciana Mirella Batista dos Santos

Faculdade de Enfermagem Nossa Senhora das Graças

Rua Arnóbio Marques, 310

Bairro: Santo Amaro

CEP: 50.100-130 - Recife - PE - Brasil

E-mail: tacianamirella@hotmail.com

\section{Endereço para correspondência:}

Taciana Mirella Batista dos Santos

Faculdade de Enfermagem Nossa Senhora das Graças

Rua Arnóbio Marques, 310

Bairro: Santo Amaro

CEP: 50.100-130 - Recife - PE - Brasil

E-mail: tacianamirella@hotmail.com 